produce the surface film as determined by Will and Knorr ${ }^{2}$ is shown by the dotted lines in Fig. 1, and it is apparent that there is a very good correlation between this quantity and the percentage of light absorbed. Both types of curvo show a similar hysteresis effect between values obtained with increasing and decreasing potential. These preliminary experiments suggest a maximum light adsorption for chemisorbed oxygen on platinum at $3500 \AA$ corresponding to a heat of adsorption of about $80 \mathrm{kcal}$. mole ${ }^{-1}$.

Will and Knorr also observod hydrogen adsorption when the potential was decreased from 0.3 to $0.0 \mathrm{~V}$, and in this region we detected an increase in light absorption, but the results were less reproducible. Hydrogen evolution is very sensitive to trace impurities and a higher degree of purity may be necessary for reproducible results at these potentials.

Large changes in tho percentage light absorbed with change in potential have also been observed for the oxygen adsorption on gold in $0.5 \mathrm{M}$ sulphuric acid, and also during the anodic dissolution of gold in aqueous cyanide solution. The latter results indicate that adsorbed species can be determined by this method whilo appreciable currents are flowing.

I thank Dr. D. E. Scaife, C.S.I.R.O., Melbourne, for his assistance in the application of the spectrophotometer to this work.

C.S.I.R.O.

D. F. A. KоCH

Division of Mineral Chemistry, Melbourne.

1 Slygin, A., and Frumkin, A., Acta physicochim. U.R.S.S., 3, 791 (1935). Will, F. G., and Knorr, C. A., Z. Elektrochem., 64, 258 (1960).

${ }^{3}$ Conway, B. E., Gileadi, E., and Dzieciuch, M., Electrochim. Acta, 8, 143 (1963).

\section{New Elements as Potential Refractories}

Examination of a Lothar-Meyer plot with reference to the synthesis of elements up to 102 , and the possibility of producing even higher elements, lead to some rather interesting speculations. On observation of the LotharMeyer plot of melting points (Fig. 1) several different types of characteristic periodic variations become apparent. Within Groups I $A$ (lithium to cæsium), I $B$ (zinc to mercury), II $A$ (beryllium to barium), IIIA (boron to thallium), IV $A$ (carbon to lead) and IVB (titanium to hafnium) the melting points tend to decrease with increasing atomic number. Within groups VB (vanadium to tantalum), VI $A$ (oxygen to polonium), VI $B$ (chromium to tungsten), VII $A$ (fluorine to astatine), VII $B$ (manganese to rhenium), VIII A (helium to radon) and VIII $B$ (iron to osmium) the melting points tend to increase with increasing atomic number. Groups $\operatorname{III} B$ (scandium to lanthanum), VA (nitrogen to bismuth) and VIII $B$ (cobalt to iridium and nickel to platinum) exhibit an intermediate behaviour in which the melting points first increase and then decrease with increasing atomic number; and group I $B$ (copper to gold) exhibits a slight minimum.

The second type, in which the melting point increases, is of interest here, with major emphasis on groups VI $B$ and VII $B$. Thus, if one may be permitted a small extrapolation, which, in view of Mendeleev's signal success, may not be too inconceivable or impertinent, it may be predicted that eka-tungsten and eka-rhenium will be even more refractory than tungsten or rhenium. The assignment of elements $90-103$ to the actinide series by Seaborg ${ }^{1}$ allows one to predict, by analogy, that elements 106 and 107 will be eka-tungsten and eka-rhenium, respectively. (If the elements 90-103 are not assigned to an inner transition series, then eka-tungsten would be uranium, and its melting point should be much higher. Its comparatively low melting point may even be cited as evidence to support the Seaborg assignments.) Extrapolation of the melting points in Fig. 1 then indicates a melting point of about $4,200^{\circ} \mathrm{K}$ for elements 106 and 107. Due to the diminutive half-lives predicted for elements above 102, the practical value of these observations is not immediately apparent. However, because of the intriguing theoretical implications, and the present inter yst in high-temperature refractories for rocket, fission and fusion applications, they are being presented here. As refractories these elements might be useful as nuclear fuel elements which could be operated for extended periods at temperatures well in excess of those possible with present materials.

Chemistry Division,

IIT Research Institute,

Chicago, Illinois.

${ }^{2}$ Friedlander, G., and Kennedy, J. W., Introduction to Radiochemistry. 274 (John Wiley and Sons, Inc., New York, 1949).

\section{Synthesis of 4-Methylene-DL-proline: a Naturally Occurring Racemic Amino-acid}

Rotational and other data from the synthesis of an optically active derivative ${ }^{1}$ have shown that 4 -methyleneproline $(\mathrm{I})$ isolated under non-epimerizing conditions from loquat seeds ${ }^{2}$ is racemic. The suspected biogenetic precursor, $\gamma$-methyleneglutamic acid, on the other hand. has been found only in optically active form ${ }^{3}$, although in different plant sources. ${ }^{4}$. In view of the rare occurrence of racemic amino-acids in Nature we wish to record the following simple synthesis of 4-methylene-DL-proline, along with direct comparison evidence confirming its identity with the natural compound.

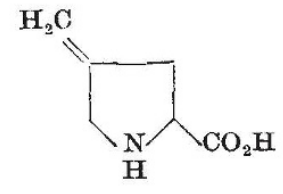

I

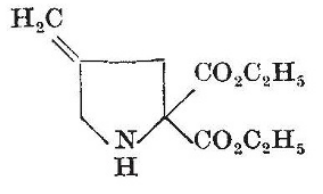

II
Alkylation of diethyl aminomalonate (used as the hydrochloride (Aldrich Chemical Co., Inc., Milwaukee, Wisconsin)) with 1,3-dichloro-2-methylenepropane ${ }^{5}$ in ethanol at $55^{\circ}$ in the presence of sodium ethoxide (three equivalonts) afforded, in 60 per cent yield, the mothylene- 